\title{
Presynaptically Expressed Long-Term Potentiation Increases Multivesicular Release at Parallel Fiber Synapses
}

\author{
Vanessa A. Bender, Jason R. Pugh, and Craig E. Jahr \\ Vollum Institute, Oregon Health \& Science University, Portland, Oregon 97239
}

At a number of synapses, long-term potentiation (LTP) can be expressed by an increase in presynaptic strength, but it is unknown whether presynaptic LTP is expressed solely through an increase in the probability that a single vesicle is released or whether it can increase multivesicular release (MVR). Here, we show that presynaptic LTP decreases inhibition of AMPA receptor EPSCs by a low-affinity antagonist at parallel fiber-molecular layer interneuron (PF-MLI) synapses. This indicates that LTP induction results in larger glutamate concentration transients in the synaptic cleft, a result indicative of MVR, and suggests that MVR can be modified by long-term plasticity. A similar decrease in inhibition was observed when release probability $\left(P_{\mathrm{R}}\right)$ was increased by forskolin, elevated extracellular $\mathrm{Ca}^{2+}$, and paired-pulse facilitation. Furthermore, we show that MVR may occur under baseline physiological conditions, as inhibition increased when $P_{\mathrm{R}}$ was lowered by reducing extracellular $\mathrm{Ca}^{2+}$ or by activating presynaptic adenosine receptors. These results suggest that at PF-MLI synapses, MVR occurs under control conditions and is increased when $P_{\mathrm{R}}$ is elevated by both short- and long-term plasticity mechanisms.

\section{Introduction}

Long-term potentiation (LTP) is an essential component of many models of learning and memory. LTP can be mediated by changes on either side of the synaptic cleft, either presynaptically through an increase in transmitter release or postsynaptically through the insertion of additional glutamatergic receptors (Nicoll and Malenka, 1995). LTP expressed presynaptically has been observed at cerebellar parallel fiber (PF) synapses, hippocampal mossy fiber synapses, and corticothalamic synapses (Zalutsky and Nicoll, 1990; Salin et al., 1996; Castro-Alamancos and Calcagnotto, 1999; Rancillac and Crépel, 2004). The induction of presynaptic LTP at these synapses is independent of postsynaptic NMDA receptor activation and is instead mediated by a rise in presynaptic $\mathrm{Ca}^{2+}$, activation of adenylyl cyclase, and the protein kinase A (PKA) pathway (Weisskopf et al., 1994; Salin et al., 1996), and modification of release machinery proteins RIM1 $\alpha$ and Rab3a (Castillo et al., 1997, 2002; Lonart et al., 2003). Because presynaptic LTP does not affect basal- or activitydependent presynaptic $\mathrm{Ca}^{2+}$ dynamics (Regehr and Tank, 1991; Chen and Regehr, 1997; but see Qiu and Knöpfel, 2007), it is thought that the changes in RIM $1 \alpha$ and Rab3a result in enhanced coupling between $\mathrm{Ca}^{2+}$ and release (Lonart et al., 2003).

Expression of presynaptic LTP may result from an increase in the number of synapses that release a single vesicle, but it could also increase the probability that multiple vesicles are released from individual synapses. Multivesicular release (MVR) has been

Received May 4, 2009; revised July 29, 2009; accepted Aug. 2, 2009.

This work was supported by National Institutes of Health (NIH) grants (MH074989), NIH training grants (DK007680 and NS007381; V.A.B. and J.R.P., respectively), and a Tartar Trust Fellowship (V.A.B.). We thank the Jahr laboratory members and Dr. Kevin J. Bender for discussions and critical readings of this manuscript.

Correspondence should be addressed to Craig E. Jahr, Vollum Institute L474, Oregon Health \& Science University, 3181 Southwest Sam Jackson Park Road, Portland, OR 97239. E-mail: jahr@ohsu.edu.

D01:10.1523/JNEUROSCI.2123-09.2009

Copyright $\odot 2009$ Society for Neuroscience ～0270-6474/09/2910974-05\$15.00/0 observed at synapses with initially high release probability $\left(P_{\mathrm{R}}\right)$ and when $P_{\mathrm{R}}$ is transiently increased during short-term plasticity (Tong and Jahr, 1994; Wadiche and Jahr, 2001; Oertner et al., 2002; Foster et al., 2005; Biró et al., 2006; Christie and Jahr, 2006). It is unknown whether long-term plasticity such as presynaptic LTP can enhance MVR.

We studied presynaptic LTP at PF-molecular layer interneuron (MLI) synapses in rat cerebellum. We assayed MVR by measuring the inhibition of AMPA receptor (AMPAR)-mediated EPSCs by the low-affinity antagonist $\gamma$-D-glutamylglycine $(\gamma$ DGG). We found that presynaptic LTP is expressed, in part, by an increase in MVR. A similar increase in MVR was observed when $P_{\mathrm{R}}$ was increased by forskolin, elevated extracellular $\mathrm{Ca}^{2+}$, and short-term facilitation, suggesting that an increase in $P_{\mathrm{R}}$ underlies the enhancement of MVR after presynaptic LTP induction. The degree of MVR covaried with $P_{\mathrm{R}}$; MVR decreased when we lowered $P_{\mathrm{R}}$ by reducing extracellular $\mathrm{Ca}^{2+}$ or by applying an adenosine receptor agonist. Thus, at PF-MLI synapses, MVR occurs under control conditions and is increased when $P_{\mathrm{R}}$ is elevated by both short- and long-term plasticity mechanisms.

\section{Materials and Methods}

Coronal cerebellar slices $(300 \mu \mathrm{m})$ were cut from Sprague Dawley rats aged postnatal day 15-19 in accordance with Oregon Health \& Science University Institutional Animal Care and Use Committee guidelines. Rats were anesthetized, decapitated, and the brain was rapidly removed in ice-cold cutting solution containing (in mM) 110 choline chloride, 25 glucose, $25 \mathrm{NaHCO}_{3}$, 11.5 sodium ascorbate, $7 \mathrm{MgCl}_{2}$, 3 sodium pyruvate, $2.5 \mathrm{KCl}, 1.25 \mathrm{NaH}_{2} \mathrm{PO}_{4}$, $0.5 \mathrm{CaCl}_{2}$. Slices were cut (VT1000S; Leica) from the vermis and incubated at $34^{\circ} \mathrm{C}$ for $30 \mathrm{~min}$, then at room temperature in artificial CSF (ACSF) containing (in mM) $124 \mathrm{NaCl}, 26 \mathrm{NaHCO}_{3}, 10$ glucose, $3 \mathrm{KCl}, 2 \mathrm{CaCl}_{2}, 1.3 \mathrm{MgCl}_{2}, 1$ $\mathrm{NaH}_{2} \mathrm{PO}_{4}, \quad 0.010$ 3-((R)-2-carboxypiperazin-4-yl)-propyl-1-phosphonic acid $\left(R\right.$-CPP). When the extracellular $\left[\mathrm{Ca}^{2+}\right]$ was changed to 1 and $3 \mathrm{~mm}$ $\mathrm{Ca}^{2+}$, the extracellular $\mathrm{Mg}^{2+}$ concentration was changed to 2.3 and $0.3 \mathrm{~mm}$, respectively. The internal solution contained (in mM) $130 \mathrm{CsMeSO}_{3}, 10$ HEPES, 10 Cs-BAPTA, $4 \mathrm{NaCl}$, $4 \mathrm{Mg}$-ATP, $0.4 \mathrm{Na}$-GTP, adjusted to pH 7.30 
A

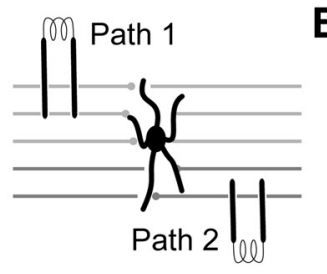

B Path 1 Path 1

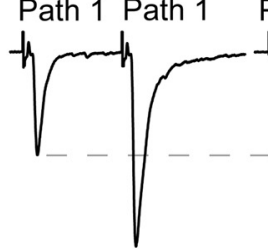

Path 2 Path 2
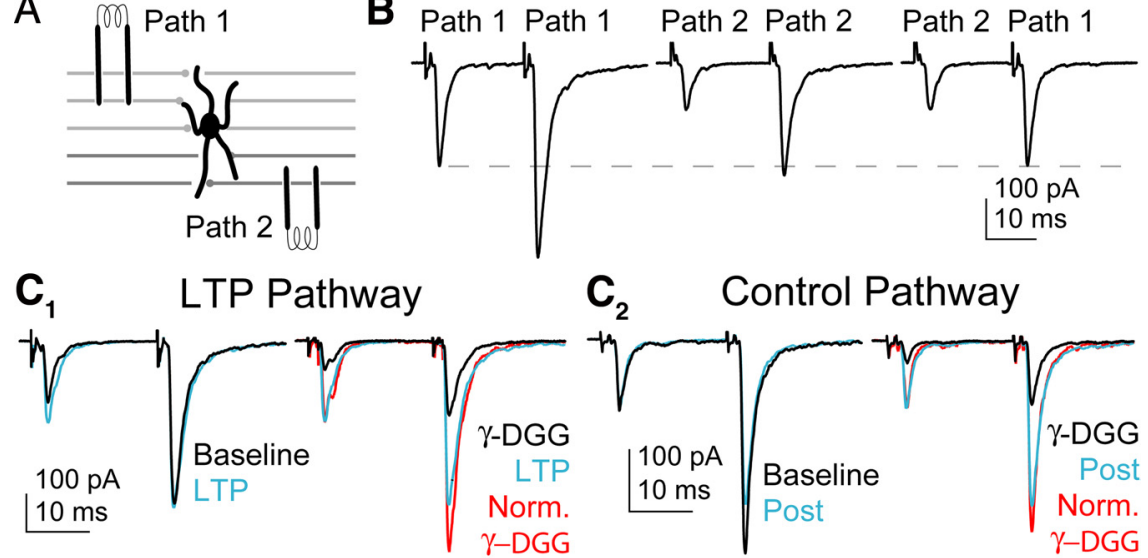

Control Pathway

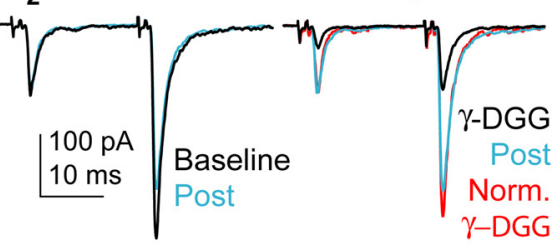

D
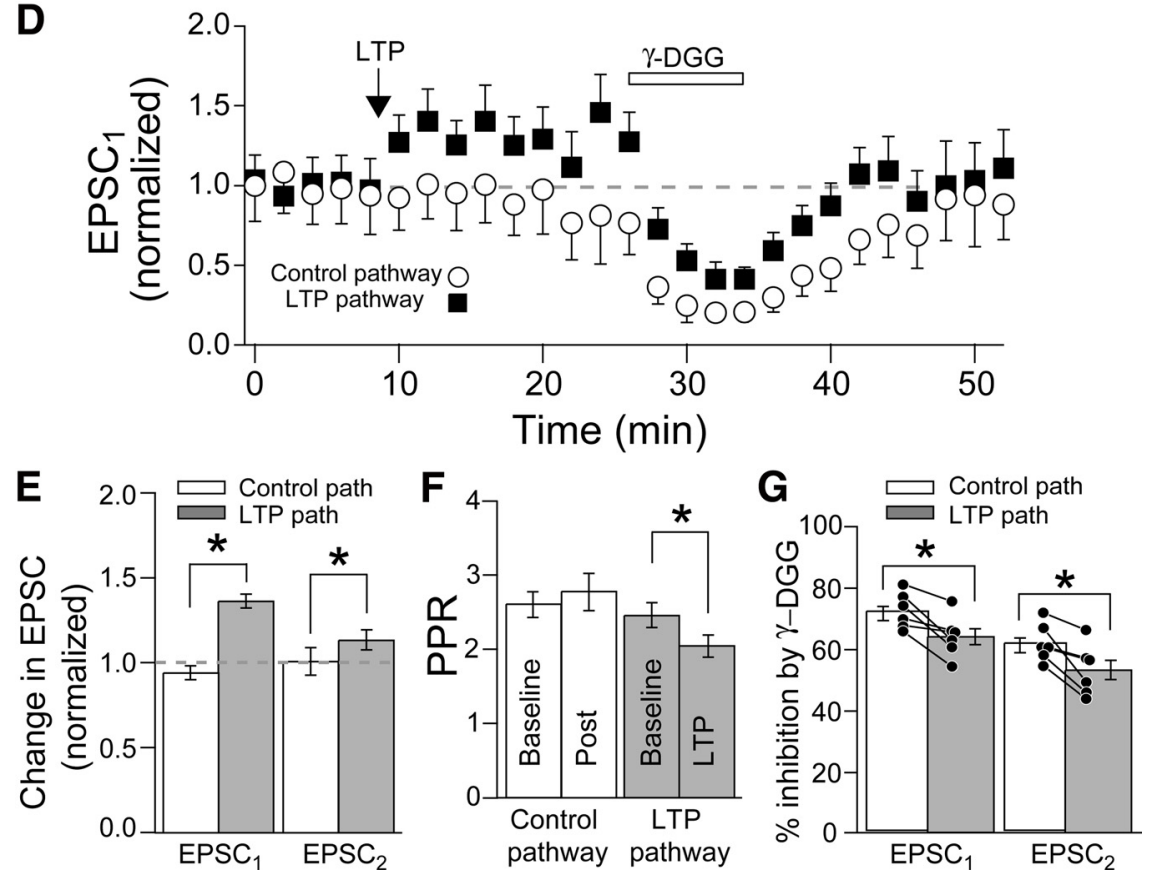

Figure 1. MVR increased after presynaptic LTP induction. $\boldsymbol{A}$, Schematic of independent PF pathway stimulation onto MLI. Stimulation electrodes were placed at different depths in the cerebellar slice. $\boldsymbol{B}$, Left, PF EPSCs evoked by paired stimuli on Path 1. Middle, EPSCs evoked by stimuli on Path 2. Right, Path 1 was stimulated 20 ms after Path 2 to check for facilitation of Path 1. Dashed line, Amplitude of the first Path 1 EPSC. C1, Left, EPSCs before (baseline) and after LTP induction (LTP). Right, Effect of $\gamma$-DGG on EPSCs after LTP induction. C2, In the same cell as C1, EPSCs evoked on the control pathway. Left, EPSCs before (baseline) and after (post) LTP was induced on the other pathway. Right, Effect of $\gamma$-DGG on EPSCs evoked on control pathway. D, Average time course of the two pathway experiments. $\boldsymbol{E}, \boldsymbol{F}$, Summary of the changes for EPSCS and PPR on both pathways. G, Percentage inhibition by $\gamma$-DGG for EPSCs compared between pathways within a single cell. Bars are SEM. Asterisks, $p<0.05$.

with $\mathrm{CsOH}(295 \mathrm{mOsm})$. Cells were held at $-80 \mathrm{mV}$ (not corrected for junction potential).

MLIs were identified by their location in the outer third of the molecular layer and their high input resistance $(>1 \mathrm{G} \Omega)$. PFs were stimulated with patch electrodes filled with $2 \mathrm{M} \mathrm{NaCl}$, positioned $50-100 \mu \mathrm{m}$ lateral to the recorded cell. Whole-cell recordings were made with 4-6 M $\Omega$ pipettes using an Axopatch 1C amplifier (Molecular Devices). Recordings were filtered at $5 \mathrm{kHz}$ and digitized at $20 \mathrm{kHz}$ (Instrutech; ITC-18) using custom programs running in IgorPro (Wavemetrics). Cells were not analyzed if the series resistance changed $>15 \%$. Recordings were made at $32-34^{\circ} \mathrm{C}$ except for a few recordings in 1 and $2 \mathrm{~mm} \mathrm{Ca}^{2+}$ which were made at room temperature $\left(21-23^{\circ} \mathrm{C}\right)$. There was no difference in inhibition by $\gamma$-DGG at the two temperatures.

Assessing changes in $\gamma$-DGG block. AMPAR-mediated EPSCs were evoked in MLIs by stimulating PFs $(5-70 \mathrm{~V}, 10 \mu \mathrm{s})$ in the presence of $R$-CPP and picrotoxin to block NMDA and $\mathrm{GABA}_{\mathrm{A}}$ receptors, respectively. Pairs of
EPSCs separated by $20 \mathrm{~ms}$ were elicited every $10 \mathrm{~s}$. After a baseline period, $\gamma$-DGG (1 mM) was bath applied for 5-10 min. Cells were analyzed if the EPSCs recovered to at least $75 \%$ of baseline after washout. The degree of inhibition by a lowaffinity, competitive antagonist, such as $\gamma$-DGG, is an indication of the size of the concentration transient of transmitter released into the synaptic cleft (Clements et al., 1992; Tong and Jahr, 1994; Wadiche and Jahr, 2001). A larger glutamate transient will compete more effectively than a smaller transient, resulting in a smaller percentage inhibition of the EPSC. The high-affinity competitive antagonist NBQX has a bound time much longer than the duration of the glutamate transient and will act in a noncompetitive manner.

Drugs. $R$-CPP and $\mathrm{N}^{6}$-cyclopentyladenosine (CPA) (Tocris Bioscience) were dissolved in ACSF. $\gamma$-DGG (Tocris Bioscience) was dissolved in $10 \mu \mathrm{M} \mathrm{NaOH}$ and ACSF. Picrotoxin (Sigma) and forskolin (Tocris Bioscience) were dissolved in DMSO, at 500 and $50 \mathrm{~mm}$, respectively.

Coefficient of variation analysis. Coefficient of variation $\left(\mathrm{CV}^{2}\right)$ was determined for cells that had a stable baseline (no significant regression) for at least 40 stimuli in each condition. CV was calculated as $\left[(\sigma)^{2}-(\sigma \text { of noise })^{2}\right] /$ mean $^{2}$.

Analysis of quantal amplitude. Asynchronous events were identified using a template function in Axograph X and then sorted manually. Average cumulative probability histograms were made by normalizing the amplitude of events to the mean during the baseline for each pathway. Data were binned in deciles, and histograms were compared using the KolmogorovSmirnov (KS) test.

Statistics. A paired $t$ test was used to compare paired experimental manipulations. A singlefactor ANOVA and Fisher's post hoc test were used when comparing more than two data sets. Significance was considered as $p<0.05$.

\section{Results}

\section{MVR increased after presynaptic} LTP induction

Presynaptic LTP is well characterized at PF synapses (Salin et al., 1996; Lonart et al., 2003; Rancillac and Crépel, 2004) and is expressed by an increase in release probability, but whether LTP increases MVR has not been explored. To test this, AMPARmediated EPSCs were evoked by stimulating two PF pathways (Fig. $1 \mathrm{~A}$ ). Pathway independence was verified by stimulating the two pathways in quick succession (20 ms) to test for paired-pulse facilitation (PPF) (Fig. $1 B$ ). The pathways were considered independent if no facilitation of the second stimulated pathway occurred.

LTP was induced by stimulating one pathway (chosen randomly) at $8 \mathrm{~Hz}$ for $30 \mathrm{~s}$. We observed significant LTP in 6 of 10 cells, similar to previous reports (Rancillac and Crépel, 2004). In those cells, LTP induction increased EPSC $_{1}$ to $134 \pm 4 \%$ of baseline and $\mathrm{EPSC}_{2}$ to $112 \pm 6 \%$ of baseline, whereas the control pathway was unchanged (Fig. $1 C, E)$. Paired-pulse ratio (PPR) decreased in the LTP pathway $(p<0.04 ; n=6$ ) (Fig. $1 C, F)$, consistent with presynaptic expression. To test for changes in MVR, we compared the inhibition of the PF-MLI EPSC in the control and poten- 

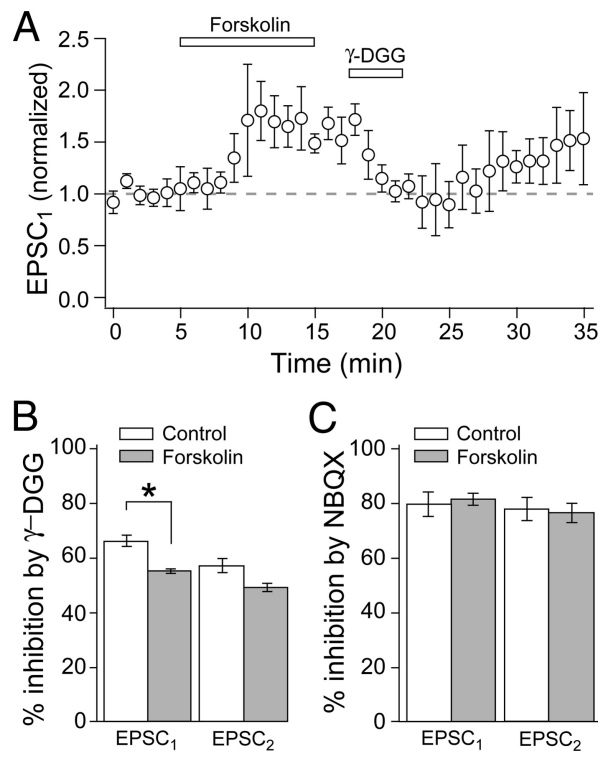

Figure 2. MVR increased with forskolin application. $A$, Time course of average EPSC1 amplitudes, in control, forskolin, and $\gamma$-DGG. $\boldsymbol{B}$, Percentage inhibition of EPSCs by $\gamma$-DGG before and after forskolin application. Control refers to cells in $2 \mathrm{~mm} \mathrm{Ca}^{2+}$. C, Percentage inhibition of EPSCs by NBQX before and after forskolin application.

tiated pathway by the low-affinity AMPAR antagonist $\gamma$-DGG ( 1 mM). $\gamma$-DGG inhibited both EPSC $_{1}$ and EPSC 2 less in the LTP pathway than in the control pathway $(p<0.02$ and $p<0.01$, respec-

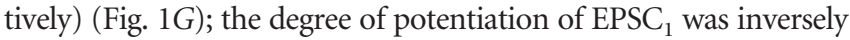
related to the amount of inhibition by $\gamma$-DGG (supplemental Fig. 1, available at www.jneurosci.org as supplemental material). In the four cells in which LTP could not be induced (EPSC $107 \pm 5 \%$; EPSC $\left._{2} 100 \pm 2 \%\right), \gamma$-DGG inhibition was not different from the control pathway or the control pathway of the six cells in which LTP was induced (supplemental Table 1, available at www.jneurosci.org as supplemental material). These results indicate that presynaptic LTP is at least partly expressed by an increase in MVR.

\section{MVR increased after forskolin}

Previous studies have shown that presynaptic LTP is mediated by the activation of PKA and is mimicked by application of the adenylyl cyclase activator forskolin (Salin et al., 1996; Chen and Regehr, 1997). Thus, forskolin should increase MVR similarly to that of LTP induction. Forskolin $(10 \mu \mathrm{M})$ increased EPSC $_{1}$ to $176 \pm 13 \%$ and EPSC $_{2}$ to $131 \pm 11 \%$ of baseline (Fig. $2 A$ ) and decreased PPR from $2.72 \pm 0.30$ to $1.99 \pm 0.17(p<0.04)$ (Fig. $2 B)$. After forskolin, $\gamma$-DGG inhibited EPSC $_{1}$ less than in control cells ( $p<0.003$; forskolin, $n=6$; control, $n=14$ ) (Fig. $2 B$ ). Inhibition of $\mathrm{EPSC}_{2}$ did not change significantly $(p=0.11)$. Forskolin did not change the inhibition by the high-affinity competitive antagonist NBQX $(n=3)$ (Fig. $2 C)$. These results show that forskolin-induced potentiation increased MVR to a similar extent as presynaptic LTP induction, consistent with the idea that these two phenomena share a common mechanism (Salin et al., 1996; Lonart et al., 1998).

\section{Paired-pulse facilitation and elevated extracellular $\left[\mathrm{Ca}^{2+}\right]$ increased MVR at PF-MLI synapses}

At synapses where MVR occurs, the degree of MVR is dependent on $P_{\mathrm{R}}$ (Tong and Jahr, 1994; Wadiche and Jahr, 2001; Foster et al., 2005; Biró et al., 2006; Christie and Jahr, 2006), but this has not been tested at PF-MLI synapses. The association of MVR and $P_{\mathrm{R}}$
A
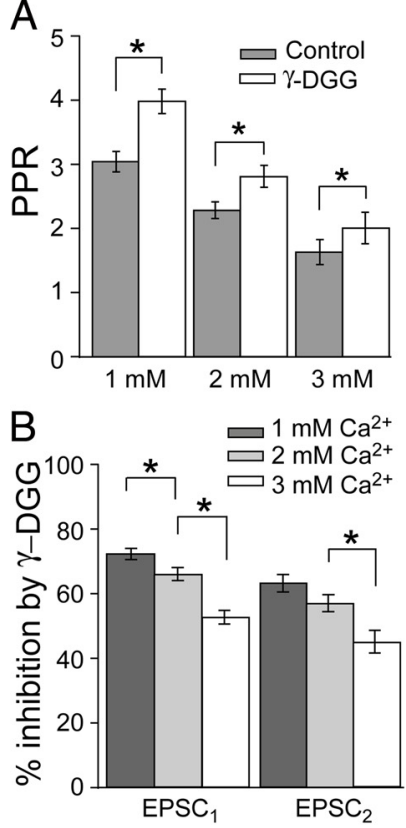

D
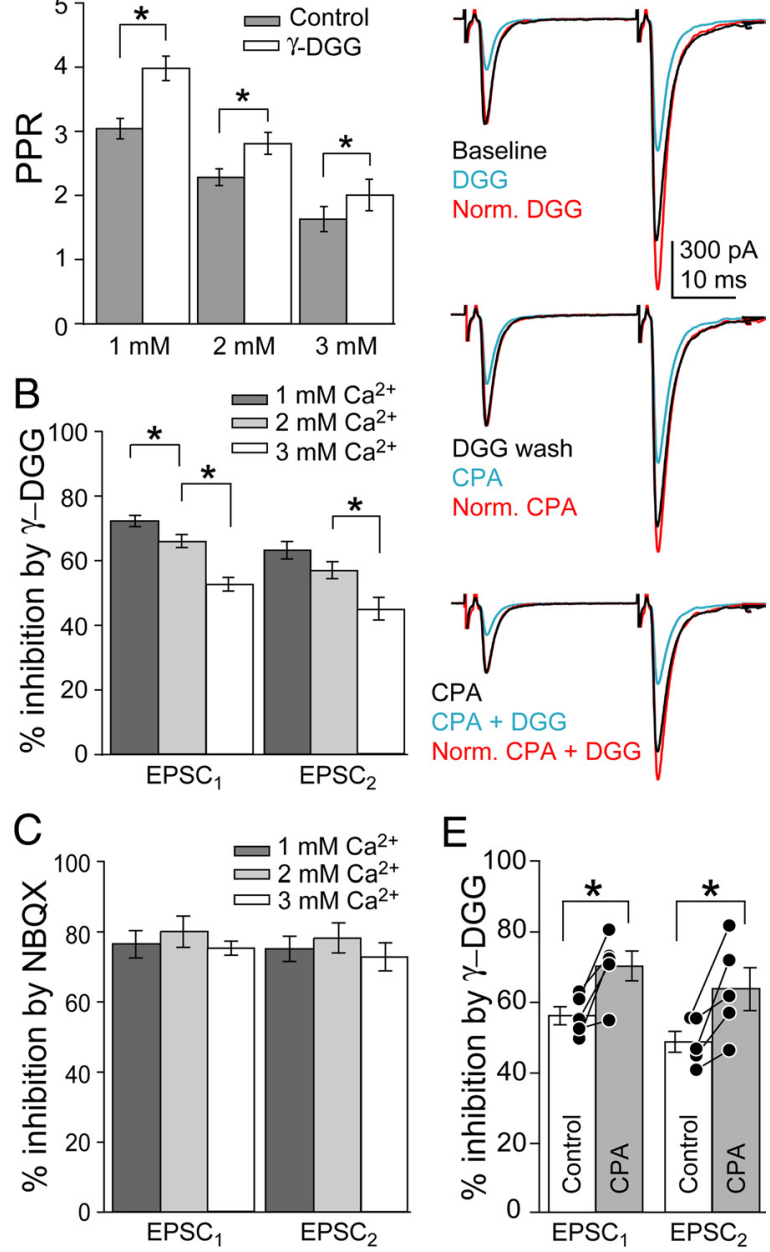

E

F

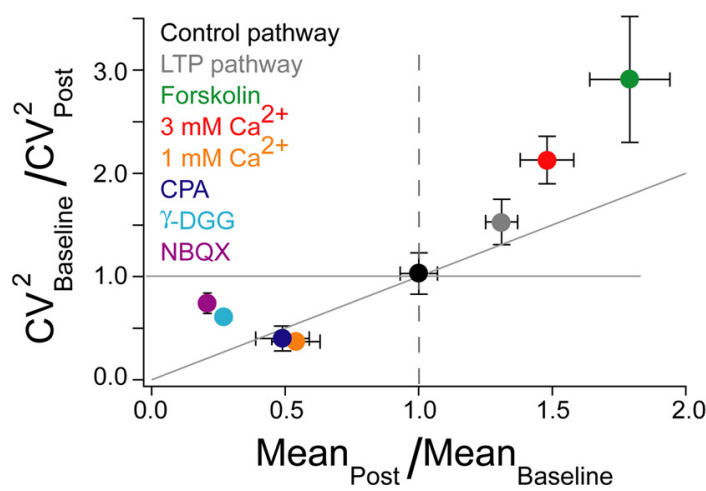

Figure 3. MVR covaried with $P_{R} \cdot A$, PPR in control conditions and during $\gamma$-DGG application in 1,2 , and $3 \mathrm{~mm} \mathrm{Ca}^{2+}$. B, Percentage inhibition by $\gamma$-DGG in 1, 2, and $3 \mathrm{~mm} \mathrm{Ca}^{2+}$ for EPSCs. C, Percentage inhibition by NBQX in 1, 2, and $3 \mathrm{~mm} \mathrm{Ca}{ }^{2+}$.D, Top, EPSCs before and after $\gamma$-DGG application. Middle, EPSCs in the same cell after $\gamma$-DGG wash and subsequent CPA application. Bottom, $\gamma$-DGG was applied again in the presence of CPA.E, Percentage inhibition of EPSCs by $\gamma$-DGG before and during CPA application within single cells. $F, \mathrm{CV}$ analysis, plotted as the ratio of $\mathrm{CV}^{-2}$ versus the mean amplitude ratio, normalized to baseline. For increases in mean amplitude (mean ratio, $>1$ ), points that fall on or above the diagonal signify a presynaptic change, whereas for decreases in mean amplitude (mean ratio, $<1$ ), presynaptic changes are reflected in points that fall on or below the diagonal.

raises the possibility that the increase in MVR associated with LTP and forskolin results exclusively from increasing $P_{\mathrm{R}}$. To test this, we compared $\gamma$-DGG inhibition in those conditions to short-term plasticity and elevated extracellular $\mathrm{Ca}^{2+}$. In control $\left(2 \mathrm{mM} \mathrm{Ca}^{2+}\right), \gamma$-DGG inhibited $\mathrm{EPSC}_{2} 9.6 \%$ less than $\mathrm{EPSC}_{1}$, increasing PPR $(p<0.001)$ (Fig. $3 A)$. Raising extracellular $\mathrm{Ca}^{2+}$ 
to $3 \mathrm{~mm}$ decreased PPR ( $p<0.05 ; n=5$ ) (Fig. 3A) and the amount of inhibition by $\gamma$-DGG for both $\mathrm{EPSC}_{1}$ and $\mathrm{EPSC}_{2}(p<$ 0.001 and $p<0.03$, respectively) (Fig. $3 B$ ), although $\gamma$-DGG still inhibited EPSC $_{2}$ less than EPSC $1(p<0.04)$ (Fig. $\left.3 B\right)$. NBQX inhibited all EPSCs equally in both 2 and $3 \mathrm{~mm}$ extracellular $\mathrm{Ca}^{2+}$ (Fig. 3C). Therefore, at PF-MLI synapses, the transient increase in $P_{\mathrm{R}}$ underlying (PPF) (Zucker and Regehr, 2002) and the increase in $P_{\mathrm{R}}$ caused by elevated extracellular $\mathrm{Ca}^{2+}$ increased MVR. These manipulations modified MVR to a similar extent as LTP, arguing that the change in MVR after LTP can be attributed to its effect on $P_{\mathrm{R}}$.

\section{MVR covaried with $P_{\mathrm{R}}$ at PF-MLI synapses}

Our data indicate that MVR increased when $P_{\mathrm{R}}$ was elevated, but it was not clear whether MVR only occurs when $P_{\mathrm{R}}$ is elevated or whether more MVR occurs in these conditions. We tested this by lowering $P_{\mathrm{R}}$. First, we lowered $P_{\mathrm{R}}$ by decreasing extracellular $\mathrm{Ca}^{2+}$ to $1 \mathrm{mM}$ from $2 \mathrm{~mm}$. This increased PPR $(p<0.001 ; n=$ 14) (Fig. $3 A$ ) and increased $\gamma$-DGG-mediated inhibition of EPSC $_{1}(p<0.02)$ (Fig. 3B). Inhibition of EPSC 2 did not increase compared with $2 \mathrm{mM} \mathrm{Ca}^{2+}(p=0.08)$ (Fig. $\left.3 B\right)$ and was still less than that of EPSC $1(p<0.001)$ (Fig. 3B). NBQX inhibited EPSCs to the same extent regardless of $\left[\mathrm{Ca}^{2+}\right]$ (Fig. $3 C$ ). Second, we also lowered $P_{\mathrm{R}}$ by applying an adenosine type 1 (A1) receptor agonist, CPA $(10 \mathrm{nM})$. A1 receptors decrease $P_{\mathrm{R}}$ at PF synapses by reducing action potential-evoked $\mathrm{Ca}^{2+}$ influx (Kreitzer and Regehr, 2000). CPA decreased $\mathrm{EPSC}_{1}$ to $53 \pm 3 \%$ and $\mathrm{EPSC}_{2}$ to $64 \pm 2 \%$ of baseline levels, resulting in increased PPR $(p<0.02 ; n=5)$ (Fig. 3D). Inhibition of both EPSCs by $\gamma$-DGG increased (EPSC ${ }_{1}$, $p<0.05$ EPSC $_{2}, p<0.03$ ) (Fig. $3 E$ ). The level of MVR was decreased by lowering extracellular $\mathrm{Ca}^{2+}$ and activation of A1 receptors, indicating that MVR occurs under control conditions and that it can be dynamically altered by changes in $P_{\mathrm{R}}$.

\section{Coefficient of variation analysis}

To verify that dynamic changes in $P_{\mathrm{R}}$ underlie the corresponding changes in MVR, we analyzed the CV of the EPSC amplitude (Bekkers and Stevens, 1990; Malinow and Tsien, 1990; Faber and Korn, 1991). Increasing extracellular $\mathrm{Ca}^{2+}$ from 2 to $3 \mathrm{~mm}$ changed $(\mathrm{CV})^{-2}$ in a manner consistent with increased $P_{\mathrm{R}}(n=$ 5) (Fig. $3 F$ ), whereas decreasing extracellular $\mathrm{Ca}^{2+}$ from 2 to 1 $\mathrm{mM}$ or applying the adenosine agonist CPA decreased $P_{\mathrm{R}}(1 \mathrm{mM}$, $n=4$; CPA, $n=3$ ) (Fig. $3 F$ ). In contrast, partial block of AMPA receptors by application of $\gamma$-DGG or NBQX changed $(\mathrm{CV})^{-2}$ only slightly, indicative of a postsynaptic effect (Bekkers and Stevens, 1990; Faber and Korn, 1991) ( $\gamma$-DGG, $n=6$; NBQX, $n=7$ ) (Fig. $3 F$ ). CV analysis indicated a presynaptic change after LTP induction, whereas the control pathway $(\mathrm{CV})^{-2}$ was unaffected $(n=6)$ (Fig. $3 F)$. Forskolin also increased $(\mathrm{CV})^{-2}(n=5)$ (Fig. $3 F$ ). Thus, CV analysis confirmed that LTP induction and forskolin increased $P_{\mathrm{R}}$ to a similar extent as raising extracellular $\mathrm{Ca}^{2+}$ to $3 \mathrm{mM}$, arguing that increased $P_{\mathrm{R}}$ is responsible for the observed enhancement of MVR for all these manipulations.

\section{Quantal amplitude does not change after presynaptic LTP induction}

We have attributed the changes in inhibition by $\gamma$-DGG to changes in MVR, although the $\gamma$-DGG manipulation actually reports changes in the glutamate concentration transient. It is possible, then, that instead of enhancing MVR, LTP increases glutamate release by increasing quantal size through changes in vesicle loading or compound fusion between vesicles before exocytosis (He et al., 2009). To test this, we examined asynchronous, presumably quantal (Atluri and Regher, 1998), events occurring up to $400 \mathrm{~ms}$ after the paired

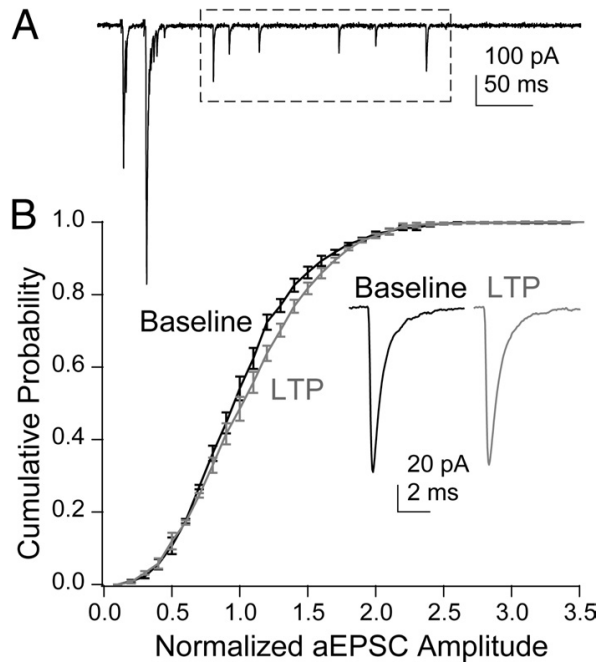

Figure 4. Quantal size is not altered by LTP induction. $\boldsymbol{A}$, Asynchronous events (box) after paired stimulation of PFs. $\boldsymbol{B}$, Cumulative probability plots of the amplitudes of aEPSCs in control and after inducing LTP. Inset, Averages of aEPSCs in the two conditions. All non-overlapping aEPSCs after the decay of the second evoked EPSC were included in the analysis.

stimuli (Fig. 4A). There was no difference in average amplitude of these events before and after LTP (baseline, $-103.8 \pm 10.6 \mathrm{pA}$; LTP, $-108.5 \pm 10.2 \mathrm{pA} ; n=4$, paired $t$ test; $p=0.23$ ), nor was there a difference in the cumulative amplitude probability distributions (Fig. $4 B$ ) (KS test; $p=0.49$ ). These results suggest that presynaptic LTP did not change quantal size and that it potentiated evoked EPSCs by increasing the number of vesicles released.

\section{Discussion}

We find that all manipulations that increase $P_{\mathrm{R}}$ at PF-MLI synapses also increase the synaptic glutamate transient. This suggests that MVR can be regulated by both short- and long-term plasticity mechanisms. Spillover from adjacent synapses can also augment the glutamate transient, but the peak amplitude of the postsynaptic response is usually unaffected by transmitter spillover, even at closely spaced synapses with little glial investiture (Wadiche and Jahr, 2001; DiGregorio et al., 2002; Christie and Jahr, 2006; Balakrishnan et al., 2009). At PF-MLI synapses, spillover and pooling of glutamate occurs only at high stimulus strength when many adjacent PFs simultaneously fire action potentials (Carter and Regehr, 2000). This would be an unlikely occurrence with the low stimulus strengths used in the present experiments. Compound fusion may also increase the synaptic glutamate transient. We find, however, that the amplitudes of asynchronous quantal events are not altered after LTP induction. This argues that compound fusion is not a common event at this synapse, unlike recent findings at the calyx of Held where asynchronous events increase in size after intense stimulation (He et al., 2009). Therefore, presynaptic LTP at PF-MLI synapses is at least partly expressed by an increase in the frequency of MVR at individual synapses rather than being mediated solely by an increase in the number of synapses that release a single vesicle. That the low-affinity antagonist technique is not particularly sensitive to changes in the glutamate transient (Wadiche and Jahr, 2001) suggests that MVR plays a prominent role in LTP expression.

At both PF synapses and mossy fiber synapses, the resting intracellular $\mathrm{Ca}^{2+}$ concentration and the action potentialevoked $\mathrm{Ca}^{2+}$ influx into presynaptic terminals are unchanged by presynaptic LTP induction (Regehr and Tank, 1991; Chen and Regehr, 1997). Instead, it is thought that presynaptic LTP is ex- 
pressed through modification of release machinery proteins RIM $1 \alpha$ and Rab3a that enhance coupling between $\mathrm{Ca}^{2+}$ and release (Lonart et al., 1998; Lonart et al., 2003). Thus, increased $\mathrm{Ca}^{2+}$ transients, as occurs during PPF and with elevated extracellular $\mathrm{Ca}^{2+}$, as well as modification of the release machinery, increase both $P_{\mathrm{R}}$ and MVR indicating that however $P_{\mathrm{R}}$ is altered, changes in MVR follow. As the mechanisms of presynaptic LTP seem to be shared by all the synapses where it has been observed, including PF, mossy fiber and corticothalamic inputs in somatosensory cortex (Salin et al., 1996; Castro-Alamancos and Calcagnotto, 1999), MVR is probably enhanced at all of these synapses after LTP induction. Indeed, optical quantal analysis at mossy fiber synapses suggested that MVR may occur after LTP (Reid et al., 2004). In addition, induction of presynaptically expressed long-term depression (LTD) can also decrease MVR (Lei and McBain, 2004). At PFs synapses, LTD is primarily expressed through postsynaptic mechanisms (Hartell, 2002; Shen et al., 2002), but it was recently found that block of presynaptic LTP reveals a form of presynaptically expressed LTD (Qiu and Knöpfel, 2009). At this and other synapses where presynaptic LTD decreases $P_{\mathrm{R}}$ (Lovinger, 2008), LTD may be expressed in part by a decrease in MVR.

PF synapses onto Purkinje cells display an increase in MVR with PPF and with increasing extracellular $\mathrm{Ca}^{2+}$ (Foster et al., 2005), similar to our present findings. We additionally show that the level of MVR that occurs at PF-MLI synapses is altered by lowering $P_{\mathrm{R}}$; MVR is decreased by lowering extracellular $\mathrm{Ca}^{2+}$ to $1 \mathrm{~mm}$ or by application of an adenosine agonist, CPA. This indicates that a basal level of MVR occurs in control conditions ( $2 \mathrm{~mm}$ extracellular $\mathrm{Ca}^{2+}$ ) even at this relatively low $P_{\mathrm{R}}$ synapse and suggests that MVR may occur more readily than previously thought.

Our results suggest that both long- and short-term forms of plasticity can influence MVR through their effects on $P_{\mathrm{R}}$. In some conditions, it is possible to observe the interaction between longterm changes and short-term plasticity resulting from PPF. More MVR always occurs on EPSC E $_{2}$ than EPS $_{1}$ at this facilitating synapse, suggesting that $P_{\mathrm{R}}$ is always higher on $\mathrm{EPSC}_{2}$ relative to $\mathrm{EPSC}_{1}$. However, forskolin does not increase MVR for $\mathrm{EPSC}_{2}$ over control levels. Forskolin increases $P_{\mathrm{R}}$ overall, but at the same time decreases PPF, resulting in no net change in $\mathrm{MVR}$ for $\mathrm{EPSC}_{2}$. Similarly, in $1 \mathrm{mM} \mathrm{Ca}^{2+}, \mathrm{EPSC}_{2}$ does not show a decrease in MVR relative to control. In this case, the decrease in $P_{\mathrm{R}}$ caused by low extracellular $\mathrm{Ca}^{2+}$ is counteracted by the enhancement of $P_{\mathrm{R}}$ resulting from increased PPF. These results show that the amount of MVR occurring during a given release event is a result of the interaction between long-term and short-term effects on $P_{\mathrm{R}}$. Thus, the magnitude of MVR may be simply a function of $P_{\mathrm{R}}$, regardless of the underlying mechanisms defining $P_{\mathrm{R}}$ at any given time.

\section{References}

Atluri PP, Regehr WG (1998) Delayed release of neurotransmitter from cerebellar granule cells. J Neurosci 18:8214-8227.

Balakrishnan V, Kuo SP, Roberts PD, Trussell LO (2009) Slow glycinergic transmission mediated by transmitter pooling. Nat Neurosci 12:286-294.

Bekkers JM, Stevens CF (1990) Presynaptic mechanism for long-term potentiation in the hippocampus. Nature 346:724-729.

Biró AA, Holderith NB, Nusser Z (2006) Release probability-dependent scaling of the postsynaptic responses at single hippocampal GABAergic synapses. J Neurosci 26:12487-12496.

Carter AG, Regehr WG (2000) Prolonged synaptic currents and glutamate spillover at the parallel fiber to stellate cell synapse. J Neurosci 20:4423-4434.

Castillo PE, Janz R, Südhof TC, Tzounopoulos T, Malenka RC, Nicoll RA (1997) Rab3A is essential for mossy fibre long-term potentiation in the hippocampus. Nature 388:590-593.

Castillo PE, Schoch S, Schmitz F, Südhof TC, Malenka RC (2002)
RIM1alpha is required for presynaptic long-term potentiation. Nature 415:327-330.

Castro-Alamancos MA, Calcagnotto ME (1999) Presynaptic long-term potentiation in corticothalamic synapses. J Neurosci 19:9090-9097.

Chen C, Regehr WG (1997) The mechanism of cAMP-mediated enhancement at a cerebellar synapse. J Neurosci 17:8687-8694.

Christie JM, Jahr CE (2006) Multivesicular release at Schaffer collateralCA1 hippocampal synapses. J Neurosci 26:210-216.

Clements JD, Lester RA, Tong G, Jahr CE, Westbrook GL (1992) The time course of glutamate in the synaptic cleft. Science 258:1498-1501.

DiGregorio DA, Nusser Z, Silver RA (2002) Spillover of glutamate onto synaptic AMPA receptors enhances fast transmission at a cerebellar synapse. Neuron 35:521-533.

Faber DS, Korn H (1991) Applicability of the coefficient of variation method for analyzing synaptic plasticity. Biophys J 60:1288-1294.

Foster KA, Crowley JJ, Regehr WG (2005) The influence of multivesicular release and postsynaptic receptor saturation on transmission at granule cell to Purkinje cell synapses. J Neurosci 25:11655-11665.

Hartell NA (2002) Parallel fiber plasticity. Cerebellum 1:3-18.

He L, Xue L, Xu J, McNeil BD, Bai L, Melicoff E, Adachi R, Wu LG (2009) Compound vesicle fusion increases quantal size and potentiates synaptic transmission. Nature 459:93-97.

Kreitzer AC, Regehr WG (2000) Modulation of transmission during trains at a cerebellar synapse. J Neurosci 20:1348-1357.

Lei S, McBain CJ (2004) Two loci of expression for long-term depression at hippocampal mossy fiber-interneuron synapses. J Neurosci 24:2112-2121.

Lonart G, Janz R, Johnson KM, Südhof TC (1998) Mechanism of action of rab3A in mossy fiber LTP. Neuron 21:1141-1150.

Lonart G, Schoch S, Kaeser PS, Larkin CJ, Südhof TC, Linden DJ (2003) Phosphorylation of RIMlalpha by PKA triggers presynaptic long-term potentiation at cerebellar parallel fiber synapses. Cell 115:49-60.

Lovinger DM (2008) Presynaptic modulation by endocannabinoids. Handb Exp Pharmacol:435-477.

Malinow R, Tsien RW (1990) Presynaptic enhancement shown by wholecell recordings of long-term potentiation in hippocampal slices. Nature 346:177-180.

Nicoll RA, Malenka RC (1995) Contrasting properties of two forms of longterm potentiation in the hippocampus. Nature 377:115-118.

Oertner TG, Sabatini BL, Nimchinsky EA, Svoboda K (2002) Facilitation at single synapses probed with optical quantal analysis. Nat Neurosci 5:657-664.

Qiu DL, Knöpfel T (2007) An NMDA receptor/nitric oxide cascade in presynaptic parallel fiber-Purkinje neuron long-term potentiation. J Neurosci 27:3408-3415.

Qiu DL, Knöpfel T (2009) Presynaptically expressed long-term depression at cerebellar parallel fiber synapses. Pflugers Arch 457:865-875.

Rancillac A, Crépel F (2004) Synapses between parallel fibres and stellate cells express long-term changes in synaptic efficacy in rat cerebellum. J Physiol 554:707-720.

Regehr WG, Tank DW (1991) The maintenance of LTP at hippocampal mossy fiber synapses is independent of sustained presynaptic calcium. Neuron 7:451-459.

Reid CA, Dixon DB, Takahashi M, Bliss TV, Fine A (2004) Optical quantal analysis indicates that long-term potentiation at single hippocampal mossy fiber synapses is expressed through increased release probability, recruitment of new release sites, and activation of silent synapses. J Neurosci 24:3618-3626.

Salin PA, Malenka RC, Nicoll RA (1996) Cyclic AMP mediates a presynaptic form of LTP at cerebellar parallel fiber synapses. Neuron 16:797-803.

Shen Y, Hansel C, Linden DJ (2002) Glutamate release during LTD at cerebellar climbing fiber-Purkinje cell synapses. Nat Neurosci 5:725-726.

Tong G, Jahr CE (1994) Multivesicular release from excitatory synapses of cultured hippocampal neurons. Neuron 12:51-59.

Wadiche JI, Jahr CE (2001) Multivesicular release at climbing fiberPurkinje cell synapses. Neuron 32:301-313.

Weisskopf MG, Castillo PE, Zalutsky RA, Nicoll RA (1994) Mediation of hippocampal mossy fiber long-term potentiation by cyclic AMP. Science 265:1878-1882.

Zalutsky RA, Nicoll RA (1990) Comparison of two forms of long-term potentiation in single hippocampal neurons. Science 248:1619-1624.

Zucker RS, Regehr WG (2002) Short-term synaptic plasticity. Annu Rev Physiol 64:355-405. 